\title{
Effect of Phenoxy Ethanol in the Growth of Certain Pathogenic Microbes
}

\author{
Priya.R, Aruna.V, Gayathri. R \\ Dr.JRK's SiddhaResearch and Pharmaceuticals Pvt., Ltd., \\ 18,19 Perumal koil street, Kunrathur, Chennai-600069
}

\begin{abstract}
Siddha system of medicine is however wonderful and miraculous, it is quite ancient andold. Hence the preparations of Siddha system of medicine may appear irrelevant if they are notmodernized and required changes in the process are not amended. Further to increase the shelflife of the wonder drugs of Siddha system requires judicious and scientific practices and precautions. The raw materials used in preparing most of the drugs range from herbal, animal,mineral to toxic metals. In this paper we report the usefulness of Phenoxy ethanol for makingthe Siddha drugs stable, effective and contemporary.
\end{abstract}

Keywords: Phenoxy ethanol, Evefresh, Siddha, Preservative

\section{Introduction}

Phenoxyethanol is one of the commonly used preservatives in various personal care and toiletry formulations (1\&2). It has the chemical formula of $\mathrm{C}_{8} \mathrm{H}_{10} \mathrm{O}_{2}$ and it has strong germicidal and germistatic property. It is composed of glycol ether, phenol ether and aromatic alcohol along with quaternary ammonium compounds.

Siddha system of medicine is an age old traditional healing method prevalent widely in southern part of India especially in Tamil Nadu (3\&8). Siddha system of medicine predominantly uses herbal, animal, mineral and metal compounds for preparing medicines $(4 \& 5)$. Therefore, controlling the microbial contamination and their growth in siddha products is quite challenging and it requiresthe use of an effective and stable preservative.

Phenoxyethanol is a colorless liquid and with high boiling point hence it can be easily dissolved in various formulations (6). It can be therefore assumed that phenoxyethanol is the best preservative for siddha drugs as they are composed predominantly of herbs.

Most of the herbs are cultivated in large scale for commercial use. The water often used for cultivating the herbs may not be potable and likely to contain various coliforms and pathogens such as Staphylococcus aureus, Pseudomonas aeruginosa, Escherichia coli etc. While using the herbs that are grown with contaminated water, the herbs also may carry these pathogens. Therefore, the preservative must be effective against the growth and multiplication of the above pathogens.In the present research article, we discuss about the usefulness of phenoxyethanol for maintaining the quality and shelf life of various Siddha formulations that are astutely formulated by Siddhars several centuries ago.

\section{Materials and Methods}

For the present study we have used a proprietary Siddha formulations- Evefresh cream of Dr.JRK's Siddha Research and Pharmaceuticals. The siddha drug contains the extracts of Aloe vera and Curcuma zedoaria in stearic acid based cream. The above cream was formulated with the preservative phenoxyethanol at $1 \%$. Then $20 \mathrm{~g}$ ofcream was dispensed separately in 9 sterilized containers. A set of 9 containers of the cream was allocated separately for the three environmental isolates of E.coli, S. aureus and P. aeruginosa.Then each container was inoculated 10,000 CFU per gram of the above microbes. Then the containers were incubated at room temperature. After an hour, one gram of the cream was collected aseptically from all the containers allocated for different species of microbes and were dispensed separately in $130 \mathrm{ml}$ of sterilized distilled water. $0.1 \mathrm{ml}$ of the sample was plated in nutrient agar plate in duplicate and incubated for 24 hours. Counting of the number of CFU's of the respective organisms that were grown in the respective plates in duplicates was done and from the above value the average was arrived. The above experiment was repeated on day 7 , day 14 and day 28 after inoculation and the reduction in the CFU from 0 day was compared.

\section{Result}

The preservative phenoxyethanol has reduced the CFU of E.coli to zero on day 28 whereas the percentage reduction of S. aureus and P. aeruginosa where 90 and 83 respectively on day 28.All the above three microbes have grown exponentially in cream which was devoid of phenoxyethanol (table 1). The studies of Ingrid Lowe and Southern in 1994 has shown that phenoxy ethanol possess broad spectrum preservative effect against diphtheria, tetanus and pertussis, Gram positive \& negative bacteriae and yeast (7). 
Effect of Phenoxy ethanol in the growth of certain pathogenic microbes

Table 1: The percentage reduction of various microbes vis-à-vis time

\begin{tabular}{|c|c|c|c|c|}
\hline \multirow[t]{2}{*}{ Organism } & \multicolumn{4}{|c|}{ \% reduction (mean) vis-à-vis time from the initial load of $10,000 \mathrm{CFU} / \mathrm{ml}$} \\
\hline & Day 0 & Day 7 & Day 14 & Day 28 \\
\hline Staphylococcus aureus & 9541 & $\begin{array}{l}2473 \\
(74 \%)\end{array}$ & $\begin{array}{l}1413 \\
(85 \%)\end{array}$ & $\begin{array}{l}918 \\
(90 \%)\end{array}$ \\
\hline E.coli & 2120 & $\begin{array}{l}1766 \\
(27 \%)\end{array}$ & $\begin{array}{l}1413 \\
(33 \%)\end{array}$ & $\begin{array}{l}0 \\
(100 \%)\end{array}$ \\
\hline Pseudomonas aeruginosa & 10247 & $\begin{array}{l}7420 \\
(28 \%)\end{array}$ & $\begin{array}{l}3180 \\
(69 \%)\end{array}$ & $\begin{array}{l}1766 \\
(83 \%)\end{array}$ \\
\hline \multirow[t]{2}{*}{ Cream without preservative } & \multicolumn{4}{|c|}{$\%$ increase vis-à-vis time from the initial load of $10,000 \mathrm{CFU} / \mathrm{ml}$} \\
\hline & Day 0 & Day 7 & Day 14 & Day 28 \\
\hline Staphylococcus aureus & 9984 & 11548 & 13654 & 15894 \\
\hline E.coli & 10830 & 11569 & 14879 & 16548 \\
\hline Pseudomonas aeruginosa & 10114 & 12548 & 14798 & 16988 \\
\hline
\end{tabular}

\section{Discussion}

The present study has clearly shown that the preservative phenoxyethanol is quite effective against three most frequently encountered pathogens viz., E.coli, S. aureus and P. aeruginosa in wide range of products. The principal source of these pathogens is soil.

The Siddha system of medicine largely uses herbal, animal, mineral and metal constituents in making Siddha drugs (9). Therefore an effective preservative is essential for preserving the siddha drugs.

Among the three microbes tested E.coli was the most susceptible to phenoxyethanol. After an hour, the initial load of E.coli had reduced to 2,120 (79\%) from its initial load of 10,000 CFU. But why the subsequent reductions were only $27 \%$ and $33 \%$ respectively for 14 and 28 days may be due to the fact that we have used the number of CFU obtained on day 0 as reference point for our calculation than the initial inoculum used for challenge study. We have maintained triplicate sets of creams for each organism and with duplicate plating. Therefore, the average could have been influenced by the likely small variation in any single plate. Further we believe that the E.coli that showed the resistance to the preservative might have (somehow?) achieved greater survival chance and that need not be concluded as resistance. Interestingly $P$. aeruginosa and S.aureushave showed instead high sensitivity to the preservative.

One may wonder why the preservative has not killed these microbes totally by day 28 as such result is only expected from any preservative. We have used 10,000 CFU/g of the organisms to challenge the product i.e., 2 lakh CFU per $20 \mathrm{~g}$. Such high inoculum is quite unlikely to enter into any product. When the inoculum size is too high, the directional meaning of the reduction from the initial load has to be interpreted sensibly than arithmetically. It means, the percentage of incorporation of preservative above $1 \%$ level is required if the load is too high. However, in any case the present findings do not discount the merit and efficacy of phenoxyethanol.

The significant reduction of the three potential pathogenic microbes by day 28 in the Siddha formulation Evefresh clearly reveals the superiority of phenoxyethanol. Even the initial load of the microbes if that falls above the assumable level in the product still phenoxyethanol can protect the product by reducing the load by 80 to $100 \%$. The organoleptic feel, emulsion stability, odour, colour, pH etc., of the product remain well within the standard despite the product is challenged with high dose of E.coli, S. aureus, P. aeruginosa. The above finding suggests that the time the product is challenged, the preservative has completely arrested further growth and multiplication of the organism if not it had killed them instantaneously.

On the contrary the cream that does not contain preservative was when challenged showed the complete signs of spoilage within two days. Further the load of the microbe has grown exponentially i.e. well above 10,000 CFU. Nevertheless, findings of the present study clearly suggest that siddha drugs can be protected and preserved well with the help of phenoxyethanol.

\section{Conclusion}

Enhancing the shelf life of siddha drugs is inevitable to achieve theglory and essence of the ancient Siddha system of medicine. Due to the likely poor shelf life of many Siddha drugs, they often fail to perform or fail to gain the acceptance of present generation despite the system having wonderful drugs and magical therapeutic benefits. Findings of the present study clearly show that phenoxy ethanol is a proven preservative for Siddha drugs. Since the raw materials used for making the Siddha drugs are of natural origin (plants, animals and animal products, minerals, metals), the coliform pathogens are the most common organisms that can easily contaminate the Siddha products through the raw materials. The target specificity of phenoxy ethanol against the common pathogenic water borne coliforms such as E.coli, S. aureus, P. aeruginosa assumes greater importance as the phenoxy ethanol can be used as the best preservative for Siddha drugs. 


\section{References}

[1]. John Krowka and Linda Loretz (2014), Phenoxyethanol as a Safe and Important Preservative in PersonalCare, Cosm \& Toil;129(5) 24-27.

[2]. Mary Ann Liebertv (1990), Final Report on the Safety Assessment of Phenoxyethanol, Journal of the American College of Toxicology, Volume 9 (2): 260-277.

[3]. Shukla S, Saraf. S (2010), Fundamental Aspect and Basic Concept of Siddha Medicines,Systematic Reviews in Pharmacy, Vol 2 (1): 48- 54 .

[4]. Narayansami V. In: Pandit SS, Introduction to the Siddha System of Medicine, T. Nagar,Madras: Anandam Research Institute of Siddha Medicine; 1975. p. 1-51.

[5]. Walter Thomas M, Rubia G, Sathiya E. Review of ethics in traditional Siddha Medicineas defined by Siddhar Theraiyar, Siddha Papers; 2009. 02 (03)

[6]. Ch. Lalitha and P. V. V. Prasada Rao (2014), Antimicrobial efficacy of low levelcosmetic preservatives, World Journal of Pharmacy and Pharmaceutical Sciences, Volume 3, (2) 1685-1696.

[7]. Ingrid Lowe, Southern.J, The antimicrobial activity of phenoxyethanol in vaccines,Letters in applied Microbiology, February 1994, Volume 18,Issue 2 Pages 115-116.

[8]. Arjun Ram, Duraisamy Arul Joseph, Selvakumar Balachandar, Vijay Pal Singh, Medicinal plants from Siddha system of medicine useful for treating respiratory diseases International Journal of Pharmaceuticals Analysis, ISSN: 0975-3079, Volume 1, Issue 2, 2009.

[9]. Sudha revathy sudharsanam, Murugesan Moonandi, Process standardization of Kara Sooda sathu parpam: A Siddha herbo mineral drug, int.J.Res.Ayurveda Pharm.5(4),Jul-Aug 2014. 